\title{
Rancang Bangun Aplikasi Wifi-Call untuk Panggilan pada Local Area Network Berbasis Android (Studi Kasus Universitas Muhammadiyah Bengkulu)
}

\author{
Rozali Toyib $^{1}$, Yulia Darnita ${ }^{2}$, Melani Sugianto ${ }^{3}$ \\ Program Studi Teknik Informatika Fakultas Teknik Universitas Muhammadiyah Bengkulu \\ Jln.Bali (Telp. (0736) 22027, 22765 Fax. (0736) 26161; e-mail: penulis1@institusi.ac.id) \\ 1Rozalitoyib@gmail.com, 2yuliadarnita@gmai.com, ${ }^{3}$ melanisugiarto@gmail.com
}

\begin{abstract}
Local Area Network Network at Muhammadiyah University of Bengkulu has been equipped with good facilities, but in it there has not been a communication system that allows Lecturers and staff to exchange information especially on the Faculty of Engineering. To use the telephone service certainly requires a lot of money and also requires the use of telephone enough that more than post paid phone service must be paid every month. In planning a VoIP network, it must have a server that functions as an IP PBX. In other conditions, such as the Faculty of Engineering University of Muhammadiyah Bengkulu this tool will be useful for lecturers and staff as a means of long-distance communication by utilizing LAN and WIFI networks to be able to connect to each other so that the work process becomes coordinated. began to apply wireless technology or wirelessly called Wireless Fidelity (WiFi0 Mobile, which was originally as a communication tool, is now more than basic functions, various features have been embedded, such as image and video processing, document processing and so on, it can not be separated from the use of Operating System on Mobile Android.The Android operating system has the main purpose to advance the innovation of mobile phone devices so that users are able to explore the capabilities and add more experience compared to other mobile platform.From the results, testing Wifi-Call Applications For Call On Local Area Network Based Android, it can be concluded as follows: Wifi-Call application made can be used in the distance less than $10 \mathrm{M}$, Trial 3 Smartphone performed well with different OS version, possibly other brand Smartphone also can work well, Dead and Live Connection This app t etap can be run because this system only use network, Response of voice resulted from system which writer make Delay more than 1 second, Wifi-Call application has been successful in testing at two different location that is campus and 1 and 2 Muhammadiyah University of Bengkulu.
\end{abstract}

Keywords: Network, Signal, Wifi, Mobile, Android

Intisari-Jaringan Local Area Network pada Universitas Muhammadiyah Bengkulu telah dilengkapi dengan fasilitas yang baik, namun di dalamnya belum terdapat suatu sistem komunikasi yang memudahkan Dosen dan staf untuk bertukar informasi khususnya pada Fakultas Teknik. Untuk menggunakan layanan telepon tentu membutuhkan biaya yang tidak sedikit dan juga memerlukan penggunaan pesawat telepon yang cukup banyak terlebih lagi layanan telepon Pasca bayar harus dibayar setiap bulannya. Dalam merencanakan suatu jaringan VoIP, harus memiliki suatu server yang berfungsi sebagai IP PBX. Dalam kondisi lain, seperti pada Fakultas Teknik Universitas Muhammadiyah Bengkulu alat ini akan berguna bagi dosen dan staff sebagai alat komunikasi jarak jauh dengan memanfaatkan jaringan LAN maupun WIFI agar bisa dapat saling terhubung sehingga proses kerja menjadi terkoordinasi. mulai menerapkan teknologi tanpa kabel (wireless) atau yang biasa di sebut dengan Wireless Fidelity (WiFio Handphone yang sedianya sebagai alat komunikasi, saat ini sudah lebih dari fungsi dasarny, berbagai macam fitur telah ditanamkan, seperti pengolah gambar dan video, pengolah dokumen dan lain sebagainya, hal ini tak lepas dari penggunaan Sistem Operasi pada HandphoneAndroid. Sistem Operasi Android memiliki tujuan utama untuk memajukan inovasi piranti telepon bergerak agar pengguna mampu mengeksplorasi kemampuan dan menambah pengalaman lebih dibandingkan dengan platform mobile lainnya. Dari hasil, pengujian Aplikasi Wifi-Call Untuk Panggilan Pada Local Area Network Berbasis Android, dapat disimpulkan sebagai berikut : Aplikasi Wifi-Call yang dibuat dapat digunakan dalam jarak kurang dari 10M, Percobaan 3 Smartphone behasil baik dengan versi OS yang berbeda-beda, kemungkinan Smartphone merek lain juga dapat berhasil baik., Dalam keadaan Koneksi Mati dan Hidup Aplikasi ini tetap dapat dijalankan karena sistem ini hanya menggunakan jaringan, Respon suara yang dihasilkan dari sistem yang penulis buat mengalami Delay lebih dari 1 detik, Aplikasi Wifi-Call ini telah berhasil melakukan pengujian di dua lokasi yang berbeda yaitu kampus dan 1 dan 2 Universitas Muhammadiyah Bengkulu.

Kata Kunci: Jaringan, Sinyal, Wifi, Handphone, Android

\section{PENDAHULUAN}

Seiring dengan tingkat mobilitas yang tinggi, beberapa tahun terakhir tengah marak perangkat bergerak atau mobile device. Salah satu perangkat mobile yang paling pesat adalah Handphone dimana hampir setiap orang memilikinya. Handphone yang sedianya sebagai alat komunikasi, saat ini sudah lebih dari fungsi dasarnya. Berbagai macam fitur telah ditanamkan, seperti pengolah gambar dan video, pengolah dokumen dan lain sebagainya. Hal ini tak lepas dari penggunaan Sistem Operasi pada Handphone. Layaknya pada komputer, Handphonepun dapat di instal berbagai macam aplikasi yang diinginkan. Android sebagai Sistem Operasi berbasis linux yang dapat digunakan di berbagai perangkat mobile. Android memiliki tujuan utama untuk memajukan inovasi 
piranti telepon bergerak agar pengguna mampu mengeksplorasi kemampuan dan menambah pengalaman lebih dibandingkan dengan platform mobile lainnya. Hingga saat ini Android terus berkembang, baik secara sistem maupun aplikasinya. Perkembangan teknologi khususnya teknologi informasi membawa perubahan yang sangat mendasar bagi dunia telekomunikasi, dalam teknologi komunikasi, komunikasi suara merupakan satu hal yang akan menjadi bagian yang sangat penting, karena saat ini komunikasi suara dianggap komunikasi yang paling praktis.Hal ini menyebabkan hadirnya teknologi pemrosesan sinyal digital yang mempunyai kemampuan modular dengan berbasis teknologi IP (Internet Protocol) yang di integrasikan antara komunikasi data dan suara.

Jaringan Local Area Network pada Universitas Muhammadiyah Bengkulu telah dilengkapi dengan fasilitas yang baik, namun di dalamnya belum terdapat suatu sistem komunikasi yang memudahkan Dosen dan staf untuk bertukar informasi khususnya pada Fakultas Teknik. Untuk menggunakan layanan telepon tentu membutuhkan biaya yang tidak sedikit dan juga memerlukan penggunaan pesawat telepon yang cukup banyak terlebih lagi layanan telepon Pasca bayar harus dibayar setiap bulannya. Dalam merencanakan suatu jaringan VoIP, harus memiliki suatu server yang berfungsi sebagai IP PBX. Dalam kondisi lain, seperti pada Fakultas Teknik Universitas Muhammadiyah Bengkulu alat ini akan berguna bagi dosen dan staff sebagai alat komunikasi jarak jauh dengan memanfaatkan jaringan LAN maupun WIFI agar bisa dapat saling terhubung sehingga proses kerja menjadi terkoordinasi.

Teknologi jaringan saat ini telah berkembang dengan pesat. Berbagai macam teknologi telah dikembangkan untuk membantu manusia dalam berkomunikasi. Kalau pada era tahun 80-an teknologi jaringan komputer hanya mengandalkan teknologi jaringan berbasis kabel, saat ini teknologi tersebut mulai banyak di tinggalkan karena beberapa keterbatasannya, seperti besarnya biaya yang harus di keluarkan oleh organisasi jika menggunakan teknologi ini (wired network),selain itu teknologi ini juga tidak flexibel karena sangat tergantung pada kabel. Saat ini kalau kitaperhatikan mulai banyak perusahaan yang mulai menerapkan teknologi tanpa kabel (wireless) atau yang biasa di sebut dengan Wireless Fidelity (WiFi). Hal ini dapat kita lihat banyaknya perusahaanyang menawarkan Hotspot Area (area yang terdapat jaringan internet berbasis $\mathrm{WiFi}$ ) yang dapat diakses oleh semua orang baik itu secara gratis maupun dengan cara registrasi ke penyedia layanantersebut. Melihat trend maraknya perusahaan yang menawarkan HotSpot Area di area publik seperti tempat perbelanjaan (mall), perpustakaan, restoran, kafe, dan bahkan hampir semua lembaga pendidikan seperti perguruan tinggi sudah menyediakan HotSpot are untuk mahasiswa mereka sebagai bagian dari fasilitas penunjang program belajar mengajar mereka. Sehingga perlu kiranya kita mengetahui tentang teknologi ini (WiFi), cara kerjanya, jenis-jenisnya, serta bagaimana sisi keamanan jaringan ini yang merupakan isu yang sangat perlu untuk diperhatikan ketika kita ingin beralihmenggunakan teknologi ini [1].

\section{Tinjauan Pustaka}

\section{A. Wireless Fidelity (Wi-Fi)}

$W i-F i$ adalah singkatan dari Wireles Fidelity yaitu seperangkat standar yang digunakan untuk komunikasi jaringan local tanpa kabel (WirelessLocalArea NetworkWLAN). yang didasari pada spesifikasi TheInstitute of Electrical and Electronics Engineer (IEEE) 802.11. Fungsinya menghubungkan jaringan dalam satu area lokal secara nirkabel. Awalnya $\mathrm{Wi}-\mathrm{Fi}$ dipakai untuk penggunaan perangkat nirkabel dan jaringan area lokal (LAN), namun saat ini lebih banyak digunakan untuk mengakses internet. Hal ini memungkinkan seseorang dengan komputer, dengan kartunirkabel (wireless card) atau personal digital assistant (PDA) untuk terhubung dengan internet dengan menggunakan titik akses(hotspot)terdekat. $W i-F i$ adalah salah satu jenis teknologi komunikasi dan informasi yang bekerja pada jaringandan perangkatWirelessLocalAreaNetwork(WLAN). $W i-F i$ merupakan merek dagang wireless $L A N$ yang diperkenalkan dan distandarisasi oleh Wi-Fi Alliance. Wi$F i$ adalah teknologi lama dan sebenarnya sudah 
disertakandibeberapanotebook Pentium 3. Tetapi pada notebook Pentium 4 dan generasi diatasnya teknologi tersebut sudah wajib hukumnya. Wi-Fi adalah satu standar jaringan wireless (Wireless Networking) tanpa kabel, hanya dengan komponen yang sesuai dapat terkoneksi ke jaringan.Hotspot adalah definisi untuk daerah yang dilayani oleh satu Access Point Wireless LAN standar $802.11 \mathrm{a} / \mathrm{b} / \mathrm{g}$, dimana pengguna (user) dapat masuk ke dalam Access Point secara bebas dan mobile menggunakan perangkat sejenis notebook, PDA atau lainnya. Sedangkan hotspot (Wi-Fi) yang akan dibahas dalam penelitian ini adalah sarana terkoneksinya jaringan internet tanpa kabel, dengan menggunakanstandarwireless fidelity, namun demikain dalam menjalankan hotspot diperlukan sarana lain, seperti Notebook, laptop, PDA yang memiliki fasilitas wireless $L A N$. Konsep teknologi nirkabel adalah teknologi yang menghubungkan dua piranti untuk bertukar data tanpa media kabel. Data dihubungkan melalui media gelombang cahaya tertentu (seperti teknologi infra merah pada remote TV) atau gelombang radio (seperti bluetooth pada komputer dan ponsel) dengan frekuensi tertentu [2].

\section{B. Local Area Network (LAN)}

LAN merupakan jaringan yang bersifat pribadi atau lokal. Jaringan ini umumnya digunakan dalam lingkup yang kecil, seperti dalam suatu kantor atau kampus. Semula LAN hanya dapat mentransimisikan paket data pada kecepatan 10 juta bit per detik, namun teknologi LAN yang baru memiliki kecepatan transmisi 10 milliar bit per detik bahkan lebih. Keuntungan LAN yang paling utama adalah pengguna jaringan tersebut dapat saling berbagi hardware dan software resource.

Umumnya Jaringan LAN dibatasi oleh area lingkungan seperti sebuah perkantoran di sebuah gedung dan biasanya jangkauannya tidak lebih dari 1 kilometer persegi. Beberapa model konfigurasi LAN biasanya berupa sebuah komputer yang dijadikan sebagai file server yang digunakan untuk menyimpan perangkat lunak ataupun sebagai perangkat lunak yang dapat digunakan oleh komputer-komputer yang terhubung ke dalam jaringan local [3].

\section{WLAN atau wi-fi}

Jaringan wireless local area network sama dengan jaringan LAN biasa, hanya saja proses transmisinya tidak memakai kabel tetapi memakai gelombang elektromagnetik atau infrared. Tetapi belakangan ini gelombang elektromagnetik lebih dominan digunakan. Jaringan wireless menggunakan electromagnetic airwaves untuk bertukar data ataupun informasi yang dibutuhkan. Gelombang radio biasa digunakan sebagai pembawa karena dapat dengan mudah mengirimkan daya kepenerima. Data ditransmisikan dengan cara ditumpangkan pada gelombang pembawa sehingga bisa diekstrak pada ujung penerima. Data ini umumnya digunakan sebagai pemodulasi dari pembawa oleh sinyal informasi yang sedang ditransmisikan. Dalam konfigurasi biasa, pemancar dengan antena, yang disebut titik akses nirkabel atau accesspoint(AP), terhubung ke LAN kabel dari lokasi tetap atau piring satelit yang menyediakankoneksiinternet(ISP). AP menyediakan layanan internet untuk sejumlah client pada ruang lingkup geografis kecil (kisaran ratusan kaki/meter) itulah yang kita kenal dengan "HotspotZone" atauHotspot. (untuk memperluas jangkauan perlu menambah jumlah AP yang ada). Sebagian besar WLAN saat ini berjalan pada standar yang dikenal sebagai 802.11 b. standar ini juga dikenal sebagai WiFi (WirelessFidelity). WLAN menggunakan standar ini untuk melakukan komunikasi dengan kecepatan 11Mbps. Sementara jaringan berkabel mempunyai kecepatan100Mbps. Tetapi standar baru dari WiFi seperti 802.11adan802.11g, sudah mampu mentransmisi data dengan kecepatan 54Mbps.

WLAN merupakan sistem komunikasi dengan udara sebagai media transmisinya. WLAN menggunakan teknologi frekuensi radio sebagai media penyimpanan data dan memiliki berbagai kemudahan bagi pengguna dalam penerapannya, antara lain :

1. Mobilitas yang tinggi, pengguna dapat mengakses informasi dimanapun sepanjangmasih dalam coverage jaringan WLAN.

2. Kemudahan dan kecepatan instalasi-instalasi jaringanWLAN lebih cepat dibandingkan dengan menggunakan kabel karena perangkat yang 
digunakan tidak perlu banyak dan mudah dikonffigurasikan.

3. Fleksibel dalam instalasi jaringan dapat dilakukan ditempat dimana jaringan LAN (Local Area Network) tidak dapat dipasang karean kendala kondisi geografis.

4. Skalabilitas jaringan WLAN dapat dikonfigurasikan dengan beberapa bentuk topologi tergantung kebutuhan pengguna seperti bentuk topologi IBSS (Independent Service Set), BSS (Bases Service Set)

Berdasarkan kemudahaan yangdidapat dengan menggunakan teknologi WLAN pengguna dapat pulamempertimbangkan kelemahaan yang ada pada teknologi tersebut dalam implmentasinya dimana terdapat pengaruh interferensi radio dan halangan akibat bangunan maupun pohon dan lai-lain [4].

\section{Android}

Android adalah sebuah sistem operasi untuk perangkat mobile berbasis linuxy ang mencakup sistem operasi, middleware, dan aplikasi.”. Android adalah sistem operasi untuk telepon seluler yang berbasis Linux. Android menyediakan platform terbuka bagi para pengembang untuk membuat aplikasi mereka sendiri. Pada awalnya dikembangkan oleh Android Inc, sebuah perusahaan pendatang baru yang membuat perangkat lunak untuk ponsel yang kemudian dibeli oleh Google Inc. Untuk pengembangannya, dibentuklah Open Handset Alliance (OHA), konsorsium dari 34 perusahaan perangkat keras, perangkat lunak, dan telekomunikasi termasuk Google, HTC, Intel, Motorola, Qualcomm, T-Mobile, dan Nvidia [6].

Android adalah sistem

operasi berbasis Linux yang dirancang untuk perangkat bergerak layar sentuh seperti telepon pintar dan komputer tablet. Android awalnya dikembangkan oleh Android, Inc, dengan dukungan finansial dari Google, yang kemudian membelinya pada tahun 2005. Sistem operasi ini dirilis secara resmi pada tahun 2007, bersamaan dengan didirikannya Open Handset Alliance, konsorsium dari perusahaan-perusahaan perangkat keras, perangkat lunak, dan telekomunikasi yang bertujuan untuk memajukan standar terbuka perangkat seluler.Ponsel
Android pertama mulai dijual pada bulan Oktober 2008. Android adalah sistem operasi dengan sumber terbuka, dan Google merilis kodenya di bawah Lisensi Apache. Kode dengan sumber terbuka dan lisensi perizinan pada Android memungkinkan perangkat lunak untuk dimodifikasi secara bebas dan didistribusikan oleh para pembuat perangkat, operator nirkabel, dan pengembang aplikasi. Selain itu, Android memiliki sejumlah besar komunitas pengembang aplikasi (apps) yang memperluas fungsionalitas perangkat, umumnya ditulis dalam versi kustomisasi bahasa pemrograman Java. Pada bulan Oktober 2013, ada lebih dari satu juta aplikasi yang tersedia untuk Android, dan sekitar 50 miliar aplikasi telah diunduh dari GooglePlay, toko aplikasi utama Android. Sebuah survei pada bulan April-Mei 2013 menemukan bahwa Android adalah platform paling populer bagi para pengembang, digunakan oleh $71 \%$ pengembang aplikasi bergerak.

Dalam paket sistem operasi Android tediri dari beberapa unsur seperti tampak pada gambar 2.1. Secara sederhana arsitektur Android merupakan sebuah kernel Linux dan sekumpulan pustaka $\mathrm{C} / \mathrm{C}++$ dalam suatu framework yang menyediakan dan mengatur alur proses aplikasi.

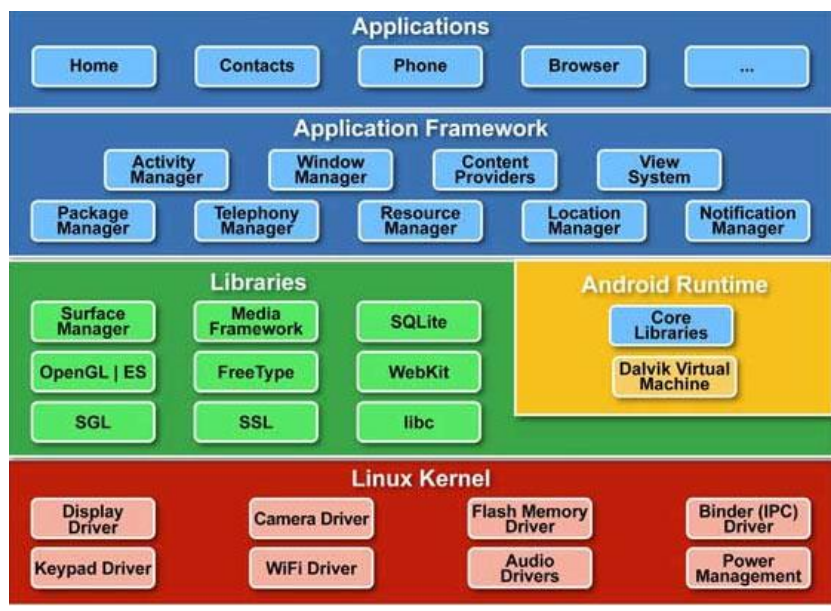

Gambar 1. Detail Anatomi Android

\section{Metodologi Penelitian}

\section{A. Tempat dan Waktu Penelitian}

Penelitian ini dilakukan di Universitas Muhammadiyah Bengkulu. Jl. Bali Po. Box, 118 Kota Bengkulu 38119 Indonesia. 


\section{B. Metode Pengumpulan Data}

Metode pengumpulan data merupakan salah satu aspek yang berperan dalam kelancaran dan keberhasilan dalam suatu penelitian. dalam penelitian ini, metode pengumpulan data yang digunakan adalah [7]:

1) Metode Observasi, yaitu mengumpulkan data dengan cara melakukan pengamatan di media-media guna mendapatkan gambaran seputar objek penelitian.

2) Metode studi pustaka, yaitu suatu metode pengumpulan data dengan cara mempelajari bukubuku atau secara

\section{Rancangan Sistem}

\section{1) Flowchart}

Adapun Rancang aplikasi wifi-call untuk panggilan pada local area network berbasis android yang di usulkan pada Universitas Muhammadiyah Bengkulu adalah seperti gambar 2.

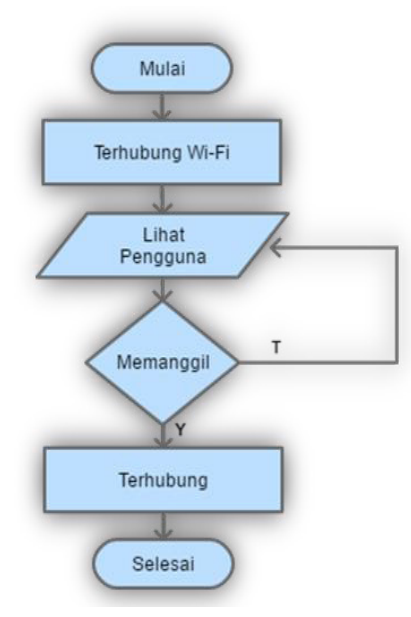

Gambar 2. Flowchart Wifi Call

\section{2) Struktur Menu}

Adapun Struktur Menu aplikasi wifi-call untuk panggilan pada local area network berbasis android yang di usulkan adalah seperti gambar 3.

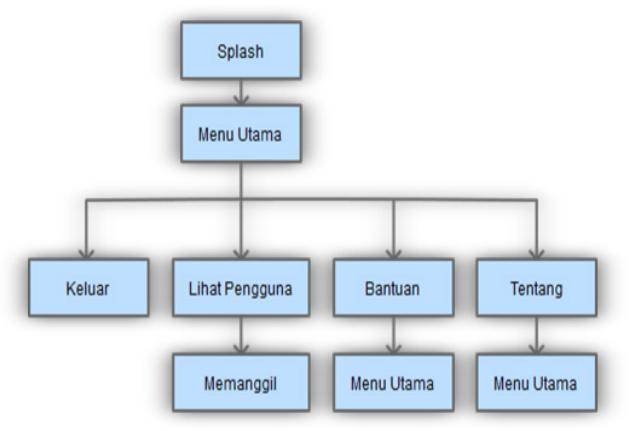

Gambar 2. Struktur Menu
3) Flow Graph

Flow Graf Wife-Call dapat dilihat pada gambar 4.

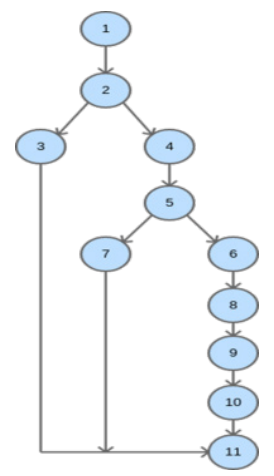

Gambar 4. Flow Graph Wifi-Call

\section{Disain Rancangan}

\section{1) Menu Utama}

Rancangan Form Menu utama terdiri dari Form Menu Panggilan, Menu Bantuan, Menu Tentang dapat dilihat pada Gambar 5.

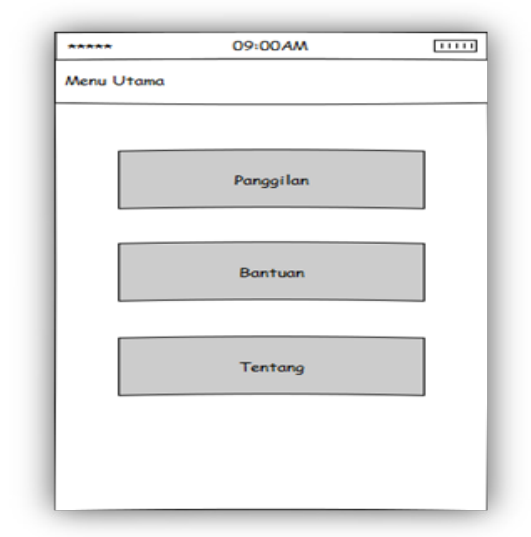

Gambar 5. Menu Utama

2) Menu Kontak

Rancangan Form Menu utama terdiri dari Form Menu Kontak Tentang dapat dilihat pada Gambar 6.

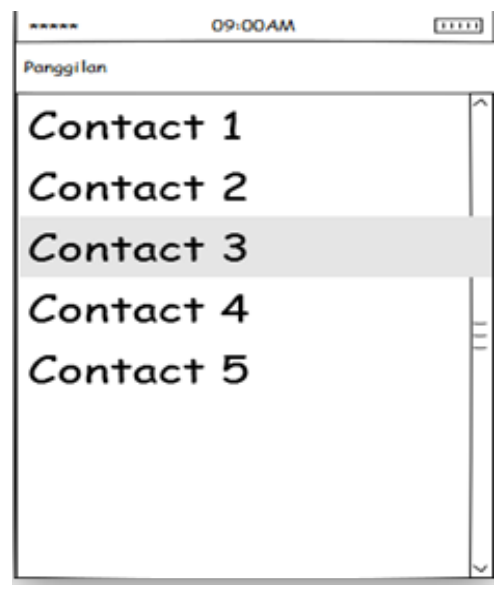

Gambar 6. Menu Kontak 


\section{3) Menu Panggilan}

Rancangan Form Menu utama terdiri dari Form Menu Panggilan Tentang dapat dilihat pada Gambar 7.

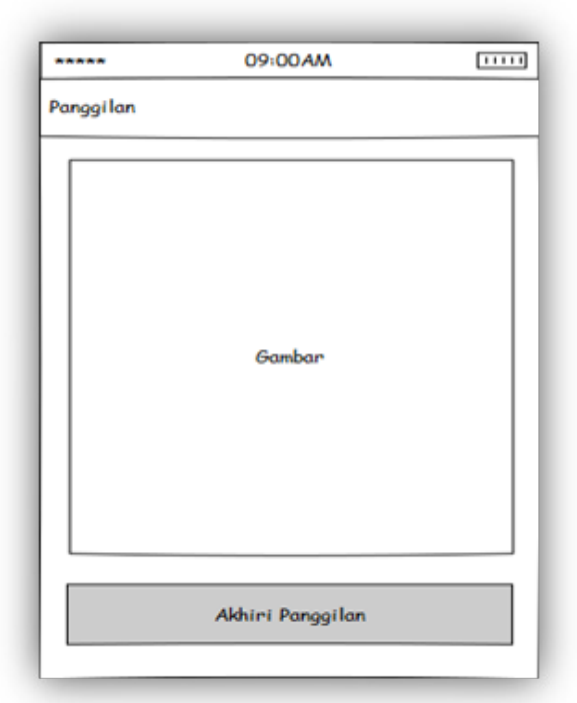

Gambar 7. Menu Panggilan

4) Menu Bantuan

Rancangan Form Menu utama terdiri dari Form Menu Bantuan Tentang dapat dilihat pada Gambar 8.

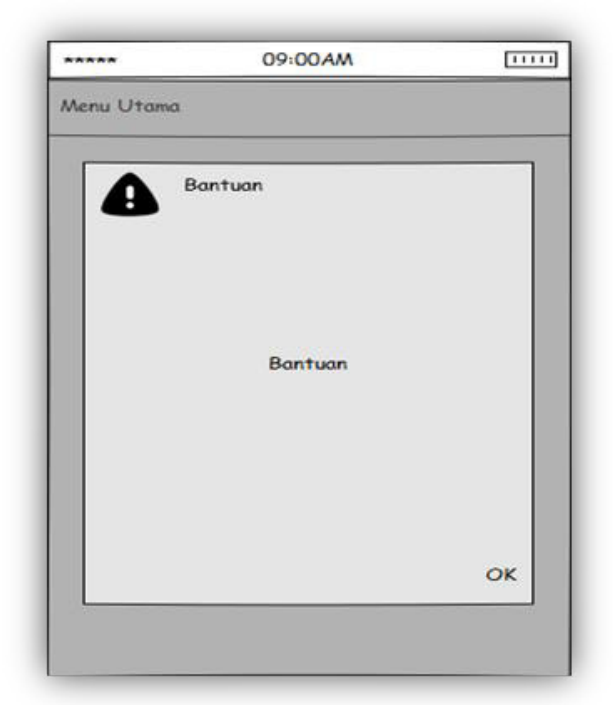

Gambar 8. Menu Bantuan

\section{E. Model Pengembangan Sistem}

Model Incremental process model merupakan metodologi yang mengkombinasi linier dan iteratif aliran proses dalam pengembangan perangkat lunak. Tujuan utama kombinasi dan iterativ ini adalah mengurangi resiko kegagalan proyek dengan cara memecah pekerjaan menjadi bagian-bagian yang lebih kecil selama pengembangan. Prinsip dasar dalam incremental process model antara lain adalah sebagai berikut: a. Serangkaian waterfall mini yang harus diselesaikan sebelum melakukan increment berikutnya

b. Semua requirement dilakukan sebelum dilakukan evolusioner

c. Fase-fase dalam setiap increment dilakukan seperti waterfall sehingga diperoleh perangkat lunak yang diinginkan dengan mengikuti fase iteratif seperti pendekatan prototyping.

(rosa A.S, 2013).

\section{IMPLEMENTASI}

\section{A. Hasil}

1) SplashScreen

Ini adalah tampilan SplashScreen ketika pertama kali kita menjalankan Aplikasi.

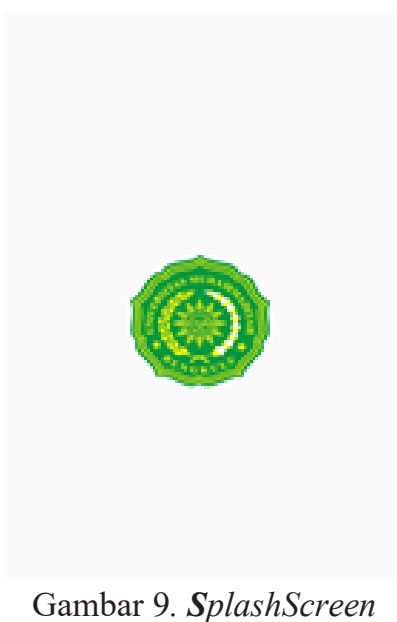

2) Menu Utama

Ini adalah tampilan menu utama setelah tampilan splashscreen, di dalam menu ini terdapat menu Panggilan, Bantuan dan tentang.

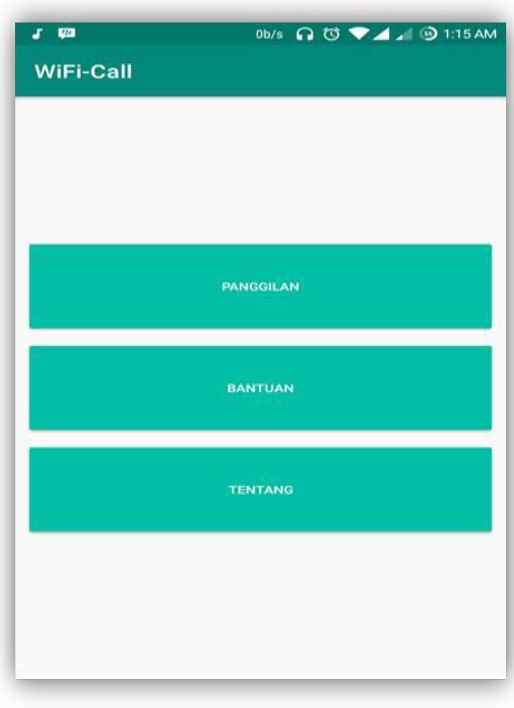

Gambar 10. Menu Utama 


\section{3) Menu Daftar Kontak}

Ini adalah tampilan menu daftar kontak, pada menu ini nantinya akan tampil secara otomatis daftar kontak pengguna yang sedang berada di dalam satu Jaringan WiFi Fakultas Teknik Universitas Muhammadiyah Bengkulu.

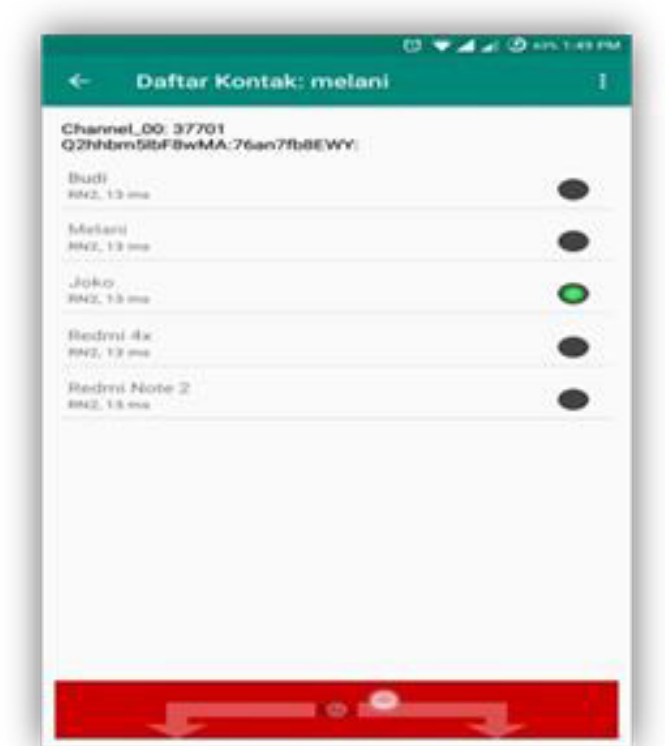

Gambar 11. Menu Daftar Kontak

\section{4) Menu Panggilan}

Ini adalah tampilan ketika pengguna melakukan panggilan kepada pengguna lainnya.

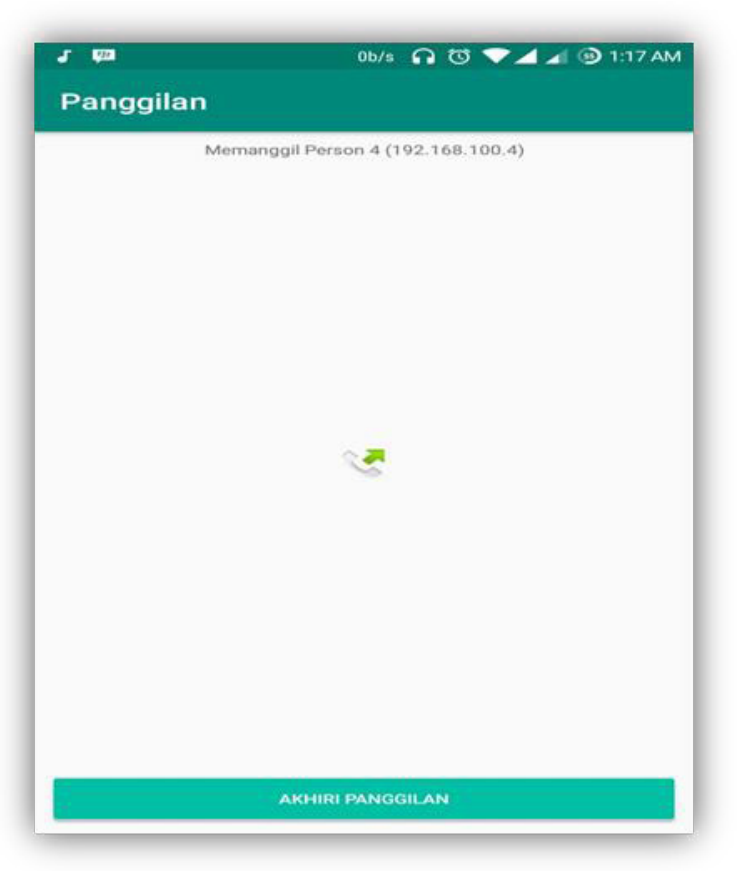

Gambar 12. Menu Panggilan

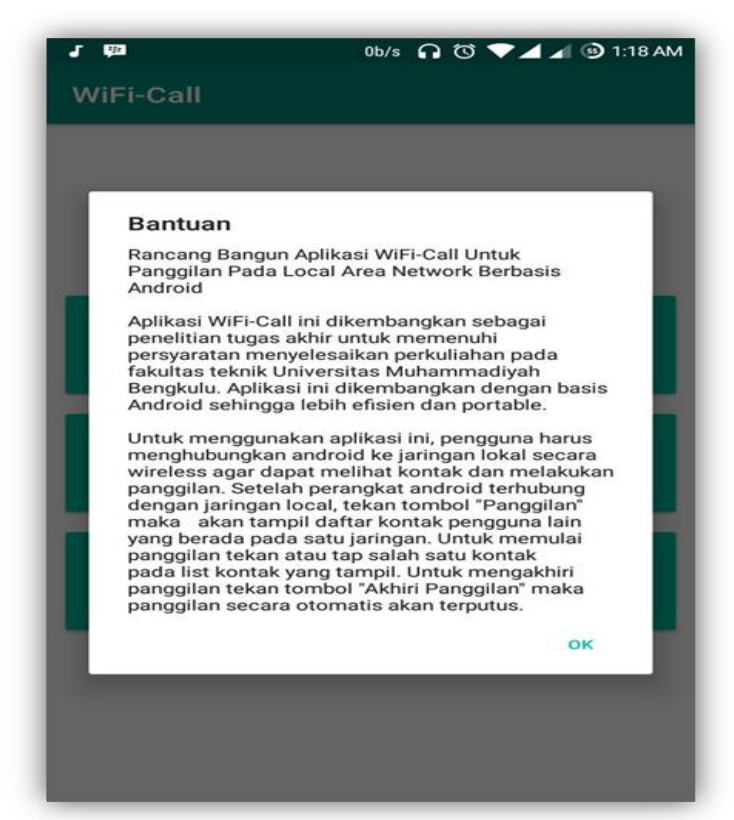

Gambar 13. Menu Bantuan

\section{B. Pembahasan}

1) Pengujian Black Box

a. Pengujian Menu Panggilan

Berikut adalah pengujian dari menu panggilan pada Tabel 1.

Tabel 1. Pengujian Menu Panggilan

\begin{tabular}{|c|c|c|c|}
\hline \multicolumn{4}{|c|}{ Kasus Hasil Uji (Data Benar) } \\
\hline $\begin{array}{c}\text { Data } \\
\text { Masukan }\end{array}$ & Yang Diharapkan & Pengamatan & Kesimpulan \\
\hline $\begin{array}{l}\text { Klik Menu } \\
\text { Panggilan }\end{array}$ & $\begin{array}{l}\text { Dapat } \\
\text { menampilkan } \\
\text { Menu Panggilan }\end{array}$ & $\begin{array}{l}\text { Menu } \\
\text { Panggilanberh } \\
\text { asil tampil }\end{array}$ & $\begin{array}{l}(\sqrt{ }) \text { Diterima } \\
\text { [] Ditolak }\end{array}$ \\
\hline $\begin{array}{l}\text { KlikTomb } \\
\text { olkembali }\end{array}$ & $\begin{array}{lr}\begin{array}{lr}\text { Dapat } \\
\text { dari }\end{array} & \text { kembali } \\
\text { Panggilan } & \end{array}$ & $\begin{array}{l}\text { Berhasil } \\
\text { kembalidari } \\
\text { menu } \\
\text { Panggilan }\end{array}$ & $\begin{array}{l}(\sqrt{ }) \text { Diterima } \\
\text { [ ] Ditolak }\end{array}$ \\
\hline
\end{tabular}

\section{b. Pengujian Menu Bantuan}

Berikut adalah pengujian dari menu Bantuan pada tabel 2 .

Tabel 2 Pengujian menu Bantuan

\begin{tabular}{|c|c|c|c|}
\hline \multicolumn{4}{|c|}{ Kasus Hasil Uji (Data Benar) } \\
\hline $\begin{array}{c}\text { Data } \\
\text { Masukan }\end{array}$ & Yang Diharapkan & Pengamatan & Kesimpulan \\
\hline Klik & Dapat & Menu Bantuan & $(\sqrt{ })$ Diterima \\
Menu & menampilkan & berhasil tampil & [ ] Ditolak \\
Bantuan & Menu Bantuan & & \\
\hline Klik & Dapat kembali & Berhasil & $(\sqrt{ })$ Diterima \\
Tombol & dari menu Bantuan & kembali dari & [ ] Ditolak \\
kembali & & menu Bantuan & \\
\hline
\end{tabular}

\section{5) Menu Bantuan}

Menu bantuan Merupakan tampilan menu yang menampilkan keterangan tentang aplikasi dan cara penggunaan aplikasi. 
c. Hasil Pengujian

Tabel 3. Hasil Pengujian

\begin{tabular}{|c|l|l|}
\hline Pengujian & \multicolumn{1}{|c|}{ Pengamatan } & Keterangan \\
\hline \multirow{4}{*}{ WLAN } & Jarak 10M $<$ & Berhasil \\
\cline { 2 - 3 } & Jarak $>10 \mathrm{M}$ & $\begin{array}{l}\text { Tidak } \\
\text { Berhasil }\end{array}$ \\
\hline \multirow{4}{*}{ Smartphone } & $\begin{array}{l}\text { Xiaomi Redmi 4A 6.0.1MM } \\
\text { B2M }\end{array}$ & Berhasil \\
\cline { 2 - 3 } & Samsung J1 00h & Berhasil \\
\cline { 2 - 3 } & Oppo F1 R2 001 & Berhasil \\
\hline \multirow{2}{*}{ System Operasi } & Ice C. Sandwich & Berhasil \\
\cline { 2 - 3 } & Jelly Bean & Berhasil \\
\hline \multirow{2}{*}{ Koneksi } & Mati & Berhasil \\
\cline { 2 - 3 } & Hidup & Berhasil \\
\hline \multirow{3}{*}{$\begin{array}{c}\text { Respon Suara } \\
\text { Lokasi Kampus } \\
\text { UMB }\end{array}$} & 1 Detik< & $\begin{array}{l}\text { Tidak } \\
\text { Berhasil }\end{array}$ \\
\cline { 2 - 3 } & $>1$ Detik & Berhasil \\
\cline { 2 - 3 } & Kampus 1 (192.168.3) & Berhasil \\
\hline \multirow{2}{*}{\begin{tabular}{c} 
Lampus 3 (192.168.9) \\
\hline
\end{tabular}} & Berhasil \\
\hline
\end{tabular}

Aplikasi Wifi-Call yang dibuat dapat digunakan dalam jarak kurang dari 10 Meter, Percobaan 3 Smartphone behasil baik dengan versi OS yang berbedabeda, Smartphone merek lain juga dapat berhasil baik., Dalam keadaan Koneksi Mati dan Hidup Aplikasi ini tetap dapat dijalankan karena sistem ini hanya menggunakan jaringan, Respon suara yang dihasilkan dari sistem mengalami Delay lebih dari 1 detik, pengujian di lakukan di Kampus 1 dan Kampus 3 di Universitas Muhasmmadiyah Bengkulu.

\section{Penutup}

\section{A. Kesimpulan}

Dari hasil, pengujian Aplikasi Wifi-Call Untuk Panggilan Pada Local Area Network Berbasis Android, dapat disimpulkan sebagai berikut :

1. Aplikasi Wifi-Call yang dibuat dapat digunakan dalam jarak kurang dari 10M.

2. Percobaan 3 Smartphone behasil baik dengan versi OS yang berbeda-beda, kemungkinan Smartphone merek lain juga dapat berhasil baik.

3. Dalam keadaan Koneksi Mati dan Hidup Aplikasi ini tetap dapat dijalankan karena sistem ini hanya menggunakan jaringan.

4. Respon suara yang dihasilkan dari sistem yang penulis buat mengalami Delay lebih dari 1 detik.

5. Aplikasi Wifi-Call ini telah berhasil melakukan pengujian di dua lokasi yang berbeda yaitu kampus dan 1 dan 2 Universitas Muhammadiyah Bengkulu.

\section{B. Saran}

Penelitian yang dilakukan tentunya tidak terlepas dari kekurangan dan kelemahan. Oleh karena itu, untuk kebaikan pengembangan sistem lebih lanjut, maka penulis menyarankan beberapa hal di antaranya:

1. Dikarenakan ilmu pengetahuan terus berkembang dan ditemukannya hal-hal baru maka basis pengetahuan dan basis aturan sistem ini perlu di update atau ditambah, sehingga data-data yang ada menjadi lebih lengkap dan kompleks.

2. Interface (tampilan) sistem yang dibangun masih tampak sederhana, sehingga dapat dikembangkan lebih menarik dengan dilengkapi fitur message dan video call.

3. Adanya delay pada aplikasi ini menjadi catatan tersendiri, sehingga pada pengembangan selanjutnya perlu dilakukan analisa pada teknik kompresi suara agar suara yang dikirim lebih ringan dan lebih cepat, sehingga delay dapat diperkecil.

\section{Daftar Pustaka}

[1] Arief Rudyanto.M, 20017, Teknologi Jaringan Tanpa Kabel (Wireless), STMIK AMIKOM, Yogyakarta.

[2] Junita Ratih, Dwi Sandi M.A, 2013, Infrastruktur Jaringan Wi-fi (wireless fidelity), Univeristas Dian Nuswantoro,Semarang

[3] Angga Wibowo. 2006. Cara Mudah Membangun LAN Panduan Praktis Instalasi Jaringan Komputer Dalam Sehari. Elex Media Komputindo, Jakarta.

[4] Sukadarmika Gede, Ngurah Indra ER, 2010, Analisis Coverage WLAN (Wireless Local Area Network) 802.11a Menggunakan Opnet Modeler, Jimbrana.

[5] Ichwan, M. 2011. Pemograman Basis Data Delphi 7 \&MySQL. Informatika, Bandung.

[6] Nazruddin Safaat H, 2011, Android (Pemograman Aplikasi Mobile Smartphone dan Tablet PC Berbasis Android). Informatika, Bandung.

[7] A.S Rosa dan Salahuddin M, 2011. Pembelajaran Rekayasa Perangkat Lunak (Terstruktur dan Berorientasi Objek), Informatika, Bandung. 